\title{
Een elektronisch zelfstudiepakket over spraak- en taalstoornissen voor de opleiding logopedie en audiologie aan de Universiteit van Gent
}

\author{
C. Mostaert, J. van Borsel, B. Morlion, K. Corthouts, A. Derese
}

\section{Samenvatting}

Inleiding: Logopedisten moeten in staat zijn verschillende spraak- en taalstoornissen te herkennen. Dikwijls zien we dat studenten deze vaardigheid pas echt kunnen leren en oefenen in rechtstreeks contact met patiënten gedurende hun stage.

Methode: Om studenten de kans te geven deze vaardigheid eerder in de opleiding te oefenen, werd op basis van audiovisueel materiaal van patiënten aan de universiteit van Gent een zelfstudiepakket ontwikkeld. Het pakket was een aanvulling op het leerboek 'Bijzondere leer van logopedie'. De studenten konden in hun eigen tempo met dit zelfstudiemateriaal aan de slag gaan. In dit artikel worden de resultaten beschreven van een eerste evaluatie van het pakket. Aan in totaal 47 studenten (27 studenten logopedie en 20 studenten audiologie) werden vragenlijsten voorgelegd.

Resultaten: Uit analyse van het gebruik van het zelfstudiepakket blijkt dat het aanvullende beeldmateriaal een meerwaarde heeft. Dit betreft vooral de illustraties bij hoofdstuk 7, 'Neurogene communicatiestoornissen'. Van tevoren was bekend dat dit hoofdstuk als moeilijk te boek staat. Opvallend zijn de verschillen tussen studenten logopedie en audiologie. Studenten logopedie toonden niet alleen een grotere waardering voor, maar ook grotere verwachtingen van het beeldmateriaal en maakten er uiteindelijk ook meer gebruik van.

Discussie en conclusies: Deze uitkomst valt wellicht deels te verklaren door verschillende interesses. Studenten logopedie kunnen de waarde van het materiaal wellicht beter inschatten aangezien zij een deel van de beelden al gezien hebben tijdens de practica. Gezien de beperkingen van e-learning (geen mogelijkheid tot onmiddellijke feedback, geen sociaal contact) zijn we ervan overtuigd dat aanvullend beeldmateriaal op het leerboek een meerwaarde kan bieden. Om deze meerwaarde te vergroten, is besloten een uitgebreider elektronisch oefenboek te maken. (Mostaert C, Borsel J van, Morlion B, Corthouts K, Derese A. Een elektronisch zelfstudiepakket over spraak- en taalstoornissen voor de opleiding logopedie en audiologie aan de universiteit van Gent. Tijdschrift voor Medisch Onderwijs 2008;27(2):80-89.)

\section{Inleiding}

Het kunnen herkennen van spraak- en taalstoornissen is een vereiste voor een logopedist. In een opleiding logopedie wordt dan ook veel aandacht besteed aan deze vaardigheid. Binnen de faculteit Geneeskunde en Gezondheidswetenschappen kan men de masteropleiding in de logopedische en audiologische weten- schappen volgen. Deze opleiding heeft twee afstudeerrichtingen: logopedie en audiologie. Daarnaast is er ook nog een professionele bacheloropleiding logopedie aan de hogescholen.

Tweedejaars bachelorstudenten logopedie en audiologie van de universiteit van Gent beschikken over een goed uitgewerkt theoretisch leerboek ('Bijzondere leer van 
logopedie'). Hierin komen verschillende spraak- en taalstoornissen aan bod. Het betreft de volgende hoofdstukken:

- Laryngectomie

- Stemstoornissen

- Articulatiestoornissen

- Taalontwikkelingsstoornissen

- Dyslexie, dysorthografie, dysgrafie en dyscalculie

- Stotteren en broddelen

- Afasie, dysartrie, apraxie en andere neurogene communicatiestoornissen

- Niet-verbale logopedische stoornissen

- Tests en testgebruik

Tijdens verschillende hoorcolleges wordt dit boek uitgediept. Daarnaast volgen alleen de studenten logopedie nog anderhalf uur practicum per week. In deze practica maken zij kennis met verschillende tests en therapiemateriaal. Ter illustratie van het leerboek worden tijdens de hoorcolleges ook videobeelden getoond. De terugkoppeling naar de praktijk blijft echter beperkt.

Het in de praktijk leren herkennen van spraak- en taalstoornissen werd tot voor kort vooral geoefend en geleerd in rechtstreeks contact met patiënten gedurende de stage. Om dit tekort op te vangen is een elektronisch zelfstudiepakket ontwikkeld, dat gebaseerd is op audiovisueel materiaal. De beschikbare 46 VHS-banden (146 uur beeldmateriaal van patiënten), die hiervoor allemaal zijn gedigitaliseerd, waren allemaal opgenomen in het Universitair Ziekenhuis te Gent. Uit de digitale versies zijn fragmenten geselecteerd die het geschiktst bevonden werden om het leerboek 'Bijzondere leer van logopedie' te verduidelijken en te illustreren. Een ICTdeskundige heeft de beelden geknipt en in een zelfstudiepakket geplaatst. De beelden werden voorzien van begeleidende teksten zodat ze in de juiste context geplaatst konden worden. Het verkregen beeldmateriaal illustreert de stoornissen die in hoofdstuk één tot en met zeven aan bod komen. We zien patiënten in spontane gesprekssituaties, in onderzoekssituaties en ook vóór en na behandelingen. Het beeldmateriaal werd eind december 2006 op het web geplaatst. Het pakket kan via een link op Minerva, het elektronisch leerplatform van de universiteit van Gent, geraadpleegd worden. Door in te loggen met hun UGent-account krijgen de studenten toegang tot het materiaal.

Ravesloot en Hasman hebben beschreven dat kennis het best beklijft als studenten ontvankelijk zijn voor de leerstof en als zij zich deze door zelfstudie eigen kunnen maken. ${ }^{1}$ Door de Dual Coding Theory weten we dat het aanbieden van leerstof op verschillende manieren bevorderlijk is voor de verwerking. Volgens deze theorie bestaan de hersenen uit twee afzonderlijke cognitieve verwerkingscentra: één voor het verwerken en opslaan van inkomende visuele informatie, en een ander voor het visualiseren en opslaan van inkomende verbale informatie. Inkomende informatie wordt dus twee maal opgeslagen, in twee verschillende cognitieve systemen. Wanneer die informatie wordt opgeroepen, wordt deze simultaan door het visuele en verbale centrum weergegeven. Ook het weer oproepen van de informatie zou op die manier vlotter verlopen. ${ }^{2}$ Ook Zhang et al. beschrijven verschillende voordelen van e-learning. De student kiest bijvoorbeeld zelf waar, wanneer en hoe vaak hij het beeldmateriaal raadpleegt en hij bepaalt het eigen studieritme ${ }^{3}$

In dit artikel worden de resultaten beschreven van een eerste evaluatie van het pakket aan de hand van aan de studenten voorgelegde vragenlijsten. Hierbij is geprobeerd een antwoord te formuleren op de volgende vragen:

- In welke mate maken de studenten gebruik van het illustratiepakket bij het 
leerboek 'Bijzondere leer van logopedie' en wat zijn hun bevindingen?

- Zijn er verschillen merkbaar in het gebruik van het pakket tussen de studenten logopedie en de studenten audiologie?

\section{Methode}

\section{Proefpersonen}

De proefpersonen $(n=51)$ studeerden allen aan de Universiteit van Gent logopedie $(n=29)$ en audiologie $(n=19)$, en stonden in het academisch jaar 2006/2007 ingeschreven voor het opleidingsonderdeel 'Bijzondere leer van logopedie'. Deze cursus wordt gegeven in het tweedejaar van de bacheloropleiding. Studenten van een schakelprogramma naar een masteropleiding audiologie $(n=3)$ beschouwden we als studenten audiologie waardoor die groep op een aantal van 22 komt.

\section{Materiaal en werkwijze}

De studenten vulden twee vragenlijsten in, de eerste vlak vóór de examenperiode (december 2006), de tweede direct na de examenperiode (februari 2007).

De eerste vragenlijst (zie box 1) richtte zich op de waardering van het leerboek. Daarnaast werd er gevraagd of de studenten het leerboek al bestudeerd hadden en hoe dat verliep. De studenten dienden hierbij de twee moeilijkste hoofdstukken aan te geven. Studenten die het boek nog niet bestudeerd hadden, werd gevraagd hun verwachtingen te beschrijven. Ook werden de verwachtingen ten aanzien van het beeldmateriaal als aanvulling op het boek gepolst. De tweede vragenlijst (zie box 2) betrof het gebruik van het aanvullende beeldmateriaal en de waardering ervan.

De data werden statistisch verwerkt met SPSS 13.0. Er is gekozen voor non-parametrische toetsen. Vanwege de beperkte aantallen kon er niet zonder meer van uitgegaan worden dat de distributie normaal was. Daarenboven wilden we zoveel mogelijk type 1 fouten vermijden.

Alle studenten ondertekenden een 'informed consent'-formulier. Alle vragenlijsten werden gecodeerd verwerkt; de vakdocent had geen inzage in deze codeverwerking.

\section{Resultaten vragenlijst 1 \\ 'Bijzondere leer van logopedie'}

Van de studenten logopedie verleenden 93\% (27/29) hun medewerking. Bij de studenten audiologie was dit percentage $91 \%$ (20/22).

\section{Waardering van de vakinhoud}

De studenten gaven hun waardering van de vakinhoud op een tienpuntsschaal. De studenten logopedie gaven een gemiddelde score van 7.5 (range 7 tot 10); de studenten audiologie gaven een iets lagere score, namelijk 7.1 (range 3 tot 9). Het verschil bleek niet significant maar er was toch duidelijk een trend (Mann-Whitney $\mathrm{U}$ test, $\mathrm{Z}=-1.807 ; \mathrm{p}=0.071)$.

\section{Vlotheid van studeren}

Er werd gescoord op een tienpuntsschaal. Vóór het begin van de examenperiode en vóór de lancering van het beeldmateriaal had $37 \%$ (10/27) van de studenten logopedie het leerboek al bestudeerd. Op de vlotheid van het studeren scoorden zij gemiddeld 6.4 (range 5 tot 8). Hoofdstuk 7 'Afasie, dysartrie, apraxie en andere neurogene communicatiestoornissen', werd door $70 \%$ van de studenten duidelijk als moeilijkste hoofdstuk beschouwd. Van de studenten audiologie had 30\% de leerstof voor aanvang van de blokperiode al bestudeerd, iets minder dus dan het aantal studenten logopedie (maar niet significant minder: chi-square, $\mathrm{p}=0.615$ ). De vlotheid van het studeren werd gescoord met 
een gemiddelde waarde van 5.6 (range 2 tot 8 ). Eén student beantwoordde dit aspect niet. Ook het merendeel van de studenten audiologie gaf aan hoofdstuk 7 als moeilijk te ervaren $(67 \%)$.

\section{Verwachtingen ten aanzien van het studeren}

De bevindingen bij de studenten die het opleidingsonderdeel nog niet bestudeerd hadden waren hetzelfde. Het ging om $63 \%$ van de studenten logopedie en om $70 \%$ van de studenten audiologie. Er werd gescoord op een tienpuntsschaal.

Op de vraag 'Hoe verwacht je dat het bestuderen van het leerboek zal verlopen?' gaven de studenten logopedie een gemiddelde score van 6.2 (range 5 tot $8 ; 1=$ helemaal niet vlot, 10 = zeer vlot). De studenten vermoedden dat de stof van hoofdstuk 7 het moeilijkste zou zijn om te leren. De studenten audiologie gaven een gemiddelde score van 6.6 (range 5 tot 8). Ook deze groep gaf aan hoofdstuk 7 als moeilijkste hoofdstuk te ervaren.

\section{Verwachtingen ten aanzien van het beeldmateriaal}

De studenten gaven op een tienpuntsschaal hun verwachtingen aan ten aanzien van de meerwaarde van het aanvullende beeldmateriaal bij het bestuderen van het boek. Eén student audiologie beantwoordde deze vraag niet. De studenten logopedie gaven een waardering van 8.3 (range 5 tot 10). Bij de studenten audiologie lag de score significant lager, namelijk 6.8 (range 4 tot 10) (Mann-Whitney U test, $\mathrm{Z}=$-3.055; $\mathrm{p}=0.002$ ).

Op de vraag of het aanvullende beeldmateriaal hen zou helpen bij het leren herkennen van stoornissen gaven de studenten opnieuw een score op een tienpuntsschaal. Eén student audiologie onthield zich van het beantwoorden van de vraag. De studenten logopedie gaven een score van 8.9 (range 7 tot 10). De studenten audiologie gaven een gemiddelde score van 8 (range 5 tot 10 ).

\section{Suggesties met betrekking tot het vak}

Tot slot konden de studenten nog enkele suggesties geven met betrekking tot het vak. Hierin uitten ze de behoefte aan oefenmateriaal op het vlak van diagnosestelling. Ook willen sommige studenten graag patiënten uitnodigen in de les. Met andere woorden: men zou de leerstof graag concreter zien.

\section{Resultaten vragenlijst 2 'Beeldmateriaal bijzondere leer van logopedie'}

Van de studenten logopedie en audiologie vulde 90\% (26/29) respectievelijk 91\% (20/22) de tweede vragenlijst in. Ze hadden allen het examen 'Bijzondere leer van logopedie' afgelegd.

\section{Bestuderen van het theoretisch leerboek}

Van de studenten logopedie had 73\% (19/26) het boek bestudeerd voordat het beeldmateriaal werd vrijgegeven. Bij de studenten audiologie lag het aantal significant lager (chi square $=5.101 ; \mathrm{p}=$ 0.024): tot $40 \%(8 / 20)$.

\section{Gebruik van het aanvullende beeldmate- riaal en effect op het studeren}

Van de studenten logopedie heeft $81 \%$ (21/26) van de studenten gebruik gemaakt van het aanvullende beeldmateriaal. Volgens $81 \%(17 / 21)$ van hen verliep het studeren daardoor vlotter. Bij de studenten audiologie lag het aantal dat het beeldmateriaal geraadpleegd had tijdens het studeren lager, maar niet significant (chi square $=2.796 ; \mathrm{p}=0.094): 58 \%(11 / 19)$. Het studeren verliep volgens $73 \%$ (8/11) van de studenten vlotter.

Ook werd nagegaan bij welke hoofdstukken er gebruik werd gemaakt van het 
beeldmateriaal en de meerwaarde ervan (zie tabel 1). Het beeldmateriaal beperkte zich tot de eerste zeven hoofdstukken. Elke student kon meerdere hoofdstukken aangeven. De illustraties bij hoofdstuk 7 'Neurogene communicatiestoornissen' bleken de meeste meerwaarde te bieden. Dat hoofdstuk kwam eerder al naar voren als het moeilijkste hoofdstuk.

De studenten die het beeldmateriaal raadpleegden, beantwoordden de vraag in welke mate dit hielp bij het verwerken van de theoretische studiestof. Op een tienpuntsschaal gaven de studenten logopedie een gemiddelde score van 6.6 (range 4 tot $9)$; de studenten audiologie gaven een gemiddelde score van 6 (range 1 tot 8) wat lager is, maar niet significant lager (MannWhitney $\mathrm{U}$ test, $\mathrm{Z}=-0.528 ; \mathrm{p}=0.598$ ).

\section{Suggesties of commentaar met betrek- king tot het beeldmateriaal}

Er waren slechts enkele opmerkingen met betrekking tot technische zaken: sommige studenten hadden problemen met het openen van de beeldfragmenten en er kwam ook wat commentaar met betrekking tot de beeld- en klankkwaliteit.

\section{Discussie en conclusies}

Uit bovenstaande resultaten blijkt dat beeldmateriaal positief beoordeeld wordt door de studenten en een meerwaarde kan betekenen voor het vak 'Bijzondere leer van logopedie'. Uit analyse van het gebruik van het beeldmateriaal bleek dat de beelden bij hoofdstuk 7 'Neurogene communicatiestoornissen' zowel voor studenten logopedie als voor studenten audiolo-

Tabel 1. Analyse van het gebruik van het zelfstudiepakket.

\begin{tabular}{|c|c|c|c|c|}
\hline \multirow[t]{2}{*}{ Hoofdstukken } & \multicolumn{2}{|c|}{ Studenten logopedie } & \multicolumn{2}{|c|}{ Studenten audiologie } \\
\hline & Bekeken & Meerwaarde & Bekeken & Meerwaarde \\
\hline \multicolumn{5}{|l|}{ Hoofdstuk 1} \\
\hline Laryngectomie & $100 \%(21 / 21)$ & $67 \%(14 / 21)$ & $100 \%(11 / 11)$ & $55 \%(6 / 11)$ \\
\hline \multicolumn{5}{|l|}{ Hoofdstuk 2} \\
\hline Stemstoornissen & $100 \%(21 / 21)$ & $67 \%(14 / 21)$ & $100 \%(11 / 11)$ & $73 \%(8 / 11)$ \\
\hline \multicolumn{5}{|l|}{ Hoofdstuk 3} \\
\hline Articulatiestoornissen & $100 \%(21 / 21)$ & $71 \%(15 / 21)$ & $100 \%(11 / 11)$ & $55 \%(6 / 11)$ \\
\hline \multicolumn{5}{|l|}{ Hoofdstuk 4} \\
\hline Taalontwikkelingsstoornissen & $100 \%(21 / 21)$ & $43 \%(9 / 21)$ & $91 \%(10 / 11)$ & $60 \%(6 / 10)$ \\
\hline \multicolumn{5}{|l|}{ Hoofdstuk 5} \\
\hline \multicolumn{5}{|l|}{ Dyslexie, dysorthografie, } \\
\hline dysgrafie en dyscalculie & $90 \%(19 / 21)$ & $32 \%(6 / 19)$ & $82 \%(9 / 11)$ & $44 \%(4 / 9)$ \\
\hline \multicolumn{5}{|l|}{ Hoofdstuk 6} \\
\hline Stotteren en broddelen & $95 \%(20 / 21)$ & $75 \%(15 / 20)$ & $82 \%(9 / 11)$ & $67 \%(6 / 9)$ \\
\hline \multicolumn{5}{|l|}{ Hoofdstuk 7} \\
\hline \multicolumn{5}{|l|}{ Neurogene communicatie- } \\
\hline stoornissen & $95 \%(20 / 21)$ & $95 \%(19 / 20)$ & $82 \%(9 / 11)$ & $89 \%(8 / 9)$ \\
\hline
\end{tabular}


gie de meeste meerwaarde te bieden. Hoofdstuk 7 werd door de studenten eerder al als moeilijkste hoofdstuk aangeduid. Het beeldmateriaal helpt hen vermoedelijk met de verwerking van de leerstof. Uit het beeldmateriaal bij hoofdstuk 5 'Dyslexie, dysorthografie, dysgrafie en dyscalculie' haalden de studenten de minste meerwaarde. Een mogelijke verklaring is dat het betreffende beeldmateriaal beperkt is. Op die manier biedt het minder ondersteuning aan het leerboek.

Er zijn verschillen in de beoordeling van de twee groepen studenten. De studenten logopedie gaven een iets hogere waarderingsscore dan de studenten audiologie. Het verschil is niet significant, maar er is wel een duidelijke trend. Een mogelijke verklaring ligt in het feit dat studenten audiologie geen practicum volgen. Zij kennen het vak enkel als een theoretische cursus. De illustraties die in het practicum aan bod komen en die het leerboek verduidelijken, gaan aan hen voorbij. Dit verklaart wellicht de iets lagere waarderingsscore ten opzichte van de vakinhoud.

Van de studenten logopedie had $73 \%$ het boek al bestudeerd voordat het beeldmateriaal beschikbaar was tegenover slechts $40 \%$ van de studenten audiologie. Dit aspect werd ook bevraagd in de eerste vragenlijst. Toen had 37\% van de studenten logopedie het boek al bestudeerd tegenover $30 \%$ van de studenten audiologie. Gedurende de tijdspanne tussen de eerste vragenlijst en het beschikbaar komen van het beeldmateriaal heeft een aantal studenten het boek nog bestudeerd. Een mogelijke verklaring zou kunnen zijn dat zij, door hun optiekeuze, meer zicht hebben op de moeilijkheden van de vakinhoud en door hun optiekeuze de leerstof beter willen beheersen door er voldoende tijd in te stoppen. Misschien zijn studenten logopedie veel gemotiveerder dan studenten audiologie voor dit vak. Het leerboek 'Bij- zondere leer van logopedie' is dan ook sterk logopediegericht en sluit daarom dichter aan bij hun optiekeuze en interessegebied.

Studenten logopedie verwachtten duidelijk meer van het beeldmateriaal dan studenten audiologie. Ook dit heeft mogelijk te maken met interesse. Een andere verklaring zou kunnen zijn dat de studenten logopedie de waarde van het materiaal kennen. Gedurende de practica maakten zij al kennis met het beeldmateriaal en konden zij de meerwaarde ervan beter inschatten. Dit heeft echter ook tot gevolg dat de resultaten met de nodige voorzichtigheid geïnterpreteerd moeten worden. Het feit dat de studenten een deel van het beeldmateriaal al kenden kan de resultaten beïnvloed hebben.

De mogelijkheid om het materiaal te kunnen raadplegen wanneer de student er zelf behoefte aan heeft, zou een groot voordeel moeten zijn. Toch merken we dat een aanzienlijk deel van de studenten het beeldmateriaal niet geraadpleegd heeft tijdens het studeren. Dit betrof vooral de studenten audiologie. Wanneer de beelden meer geïntegreerd zouden worden in de les, zouden de studenten audiologie ook kunnen ervaren wat het beeldmateriaal te bieden heeft. Op die manier zouden ze mogelijk buiten de lesmomenten meer gebruik maken van het materiaal.

Het aanbieden van ons internetonderwijs kent toch nog een aantal problemen. De studenten kunnen het beeldmateriaal alleen raadplegen via het internet. Omdat niet alle studenten over een internetverbinding beschikken, moeten we rekening houden met de groep studenten die het beeldmateriaal niet altijd kan raadplegen. Om dit tekort op te vangen, biedt de universiteit verschillende computerklassen aan waar de studenten het internet vrij kunnen raadplegen. 
Ondanks de meerwaarde van het beeldmateriaal kan het geen vervanging betekenen voor de practica omdat het slechts een deel van de inhoud van het practicum omvat. Naast het aanbieden van beeldmateriaal krijgen de studenten ook een kans om therapiemateriaal en tests van dichterbij te bekijken. Daarnaast bieden contactmomenten (face to face) tussen docent en student een aantal belangrijke voordelen. De docent kan onmiddellijk feedback geven en daardoor de studenten ook makkelijker motiveren. Daarnaast zijn contactmomenten sociale gebeurtenissen. Sommige studenten ervaren e-learning als onaangenaam door het gebrek aan contact en feedback. ${ }^{3}$

In het algemeen kunnen we stellen dat de studenten meerwaarde halen uit het aanvullende beeldmateriaal, vooral bij de hoofdstukken 2, 6 en 7. Er zijn nog enkele tekorten op het vlak van kwaliteit en kwantiteit die we kunnen oplossen door het maken van nieuwe opnames.

Om de verwachtingen van de studenten in te lossen, zal overgegaan worden op het maken van een elektronisch oefenboek, waarin zij hun vaardigheid zelf kunnen oefenen.

\section{Box 1 Vragenlijst 1 - Bijzondere leer van logopedie.}

1. Welke afstudeerrichting heeft u gekozen?

logopedie
audiologie

2. Heeft $u$ de lessen bijgewoond?

altijd

meestal

soms

nooit

3. Wat vindt $u$ van de vakinhoud?

$\begin{array}{cccccccccc}1 & 2 & 3 & 4 & 5 & 6 & 7 & 8 & 9 & 10 \\ 0 & 0 & 0 & 0 & 0 & 0 & 0 & 0 & 0 & 0\end{array}$

4. Heeft $\mathrm{u}$ het leerboek reeds bestudeerd?

$O$ ja

$\bigcirc$ neen

4.1 Zo ja, hoe verliep het studeren?

$\begin{array}{llllllllll}1 & 2 & 3 & 4 & 5 & 6 & 7 & 8 & 9 & 10\end{array}$

$1=$ helemaal niet vlot

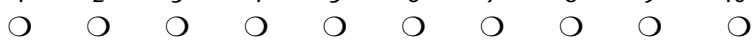

10 = zeer vlot

Welke twee hoofdstukken vond $\mathrm{u}$ het moeilijkst om te bestuderen?

- Hoofdstuk 1: Laryngectomie

- Hoofdstuk 2: Stemstoornissen

- Hoofdstuk 3: Articulatiestoornissen

- Hoofdstuk 4: Taalontwikkelingsstoornissen

- Hoofdstuk 5: Dyslexie, dysorthografie, dysgrafie en dyscalculie

- Hoofdstuk 6: Stotteren en broddelen 
- Hoofdstuk 7: Afasie, dysartrie, apraxie en andere neurogene communicatiestoornissen

- Hoofdstuk 8: Niet-verbale logopedische stoornissen

- Hoofdstuk 9: Tests en testgebruik

1: (het moeilijkste)

2:

4.2 Zo neen, hoe verwacht je dat het bestuderen van het leerboek zal verlopen?

$\begin{array}{cccccccccc}1 & 2 & 3 & 4 & 5 & 6 & 7 & 8 & 9 & 10 \\ 0 & 0 & 0 & 0 & 0 & 0 & 0 & 0 & 0 & 0\end{array}$

Welke twee hoofdstukken lijken $\mathrm{u}$ het moeilijkst om te bestuderen?

- Hoofdstuk 1: Laryngectomie

- Hoofdstuk 2: Stemstoornissen

- Hoofdstuk 3: Articulatiestoornissen

- Hoofdstuk 4: Taalontwikkelingsstoornissen

- Hoofdstuk 5: Dyslexie, dysorthografie, dysgrafie en dyscalculie

- Hoofdstuk 6: Stotteren en broddelen

- Hoofdstuk 7: Afasie, dysartrie, apraxie en andere neurogene communicatiestoornissen

- Hoofdstuk 8: Niet-verbale logopedische stoornissen

- Hoofdstuk 9: Tests en testgebruik

1: (het moeilijkste)

2:

5. Denkt $u$ dat aanvullend beeldmateriaal op het leerboek, dat $u$ vrij kunt raadplegen, $u$ zou helpen bij het verwerken van de cursus?

$\begin{array}{cccccccccc}1 & 2 & 3 & 4 & 5 & 6 & 7 & 8 & 9 & 10 \\ 0 & 0 & 0 & 0 & 0 & 0 & 0 & 0 & 0 & 0\end{array}$

6. Denkt $u$ dat $\mathrm{u}$ in staat bent om de volgende stoornissen te herkennen?

(Gelieve de stoornissen aan te duiden waarvan $u$ denkt dat $u$ ze zou herkennen.)

Laryngectomie

Stemstoornissen

Articulatiestoornissen

Taalontwikkelingsstoornissen

Dyslexie, dysorthografie, dysgrafie en dyscalculie

Stotteren en broddelen

Neurogene communicatiestoornissen

Niet-verbale logopedische stoornissen

7. Denkt $u$ dat aanvullend beeldmateriaal op het leerboek, dat $u$ vrij kunt raadplegen, $\mathrm{u}$ zou helpen bij het leren herkennen van stoornissen?

$\begin{array}{rrrrrrrrrr}1 & 2 & 3 & 4 & 5 & 6 & 7 & 8 & 9 & 10 \\ 0 & 0 & 0 & 0 & 0 & 0 & 0 & 0 & 0 & 0\end{array}$

8. Gelieve hier suggesties of commentaar met betrekking tot het vak 'Bijzondere leer van logopedie' neer te schrijven. 
Box 2 Vragenlijst 2 - Beeldmateriaal bijzondere leer van logopedie.

1. Heeft $u$ het examen 'Bijzondere leer van logopedie' afgelegd?

$O$ ja

neen

2. Had $u$ het leerboek reeds bestudeerd voor het aanvullende beeldmateriaal op het leerboek beschikbaar was?

O ja

neen

3. Heeft $u$ gebruik gemaakt van het aanvullende beeldmateriaal dat beschikbaar was via Minerva?

$\bigcirc$ ja

neen

3.1 Zo ja, verliep het studeren daardoor vlotter?

$\bigcirc$ ja

neen

4. Duid de hoofdstukken aan waarbij u gebruik gemaakt heeft van het aanvullende beeldmateriaal.

Zet ook een kruisje bij de hoofdstukken waar het beeldmateriaal volgens $u$ een echte meerwaarde betekent.

$$
\begin{array}{cc}
\begin{array}{c}
\text { Beeldmateriaal } \\
\text { geraadpleegd }
\end{array} & \begin{array}{c}
\text { Beeldmateriaal een } \\
\text { meerwaarde }
\end{array}
\end{array}
$$

- Hoofdstuk 7: Laryngectomie

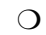

O

- Hoofdstuk 8: Stemstoornissen

- Hoofdstuk 9: Articulatiestoornissen

- Hoofdstuk 10: Taalontwikkelingsstoornissen

- Hoofdstuk 11: Dyslexie, dysorthografie, dysgrafie en dyscalculie

- Hoofdstuk 12: Stotteren en broddelen

- Hoofdstuk 13: Afasie, dysartrie, apraxie en andere neurogene communicatiestoornissen

5. In welke mate heeft het beeldmateriaal u geholpen bij het verwerken van het leerboek?

$\begin{array}{cccccccccc}1 & 2 & 3 & 4 & 5 & 6 & 7 & 8 & 9 & 10 \\ 0 & 0 & 0 & 0 & \bigcirc & \bigcirc & 0 & \bigcirc & \bigcirc & \bigcirc\end{array}$

1 = helemaal niet $10=$ zeer goed

6. Vond $\mathrm{u}$ het aangeboden beeldmateriaal overzichtelijk?

$\begin{array}{cccccccccc}1 & 2 & 3 & 4 & 5 & 6 & 7 & 8 & 9 & 10 \\ 0 & 0 & 0 & 0 & 0 & 0 & 0 & 0 & 0 & 0\end{array}$

1 = helemaal niet $10=$ zeker en vast

7. Vond $u$ het aangeboden beeldmateriaal gebruiksvriendelijk?
1
23
4
5
6
7
89
10
○
$1=$ helemaal niet
$10=$ zeker en vast

8. Gelieve hier suggesties of commentaar met betrekking tot het aanvullende beeldmateriaal neer te schrijven. 


\section{Literatuur}

1. Ravesloot JH, Hasman A. Zonder computers geen goed onderwijs in de geneeskunde. Tijdschrift voor Medisch Onderwijs 2006;25(2):96-7. [Good medical education is impossible without computers. Dutch Journal of Medical Education 2006;25(2):96-7].

2. Paivio A. Mental representations: A dual coding aproach. New York: Oxford University Press; 1986.

3. Zhang D, Zhao J, Zhou L, Numamaker J. Can e-learning replace classroom learning? Communication of the ACM 2004;47(5):75-8.

De auteurs:

Ma. C. Mostaert, wetenschappelijk medewerker, logistieke dienst onderwijsondersteuning.

Prof. dr. J. van Borsel, hoofddocent vakgroep logopedische en audiologische wetenschappen.

Ma. B. Morlion, beleidsmedewerker kwaliteitscel Onderwijs.

\section{Summary}

Introduction: Speech therapists need to be able to recognise several speech and language disorders. Often students can only learn and practise this skill through direct contacts with patients during traineeships.

Method: To enable students to practise this skill earlier in their training, the University of Ghent developed a self-study module based on audiovisual material of patients, complementary to the 'Advanced study of logopaedics' course book. Students were expected to use the module according to their personal needs and at their own pace. The current article reports the results of a student questionnaire evaluating the module. A total of 47 students (27 logopaedics and 20 audiology students) participated in the study.

Results: The results on the use made of the model suggest that the module is a valuable addition to the course book. Especially the illustrations to chapter 7, 'neurogenic communication disorders', previously identified as the most difficult chapter were greatly appreciated. There were differences between logopaedics students and audiology students, with the former showing higher appreciation and higher expectations of the module and making more use of it.

Discussion and conclusions: The differences in appreciation can probably be explained partly by differences in interest. The logopaedics students were better able to appreciate the material as they had viewed part of it already during regular training sessions. Despite the limitations of e-learning (no immediate feedback, no social contact), the visual material appears to be a valuable addition to the course book. To boost this value, we will put together a more comprehensive electronic workbook. (Mostaert C, Van Borsel J, Morlion B, Corthouts K, Derese A. An electronic self-study module of speech and language disorders for training in logopaedics and audiology at the University of Ghent. Dutch Journal of Medical Education 2008;27(2):80-89.) 